\title{
CHARACTERISATION OF RHIZOPHORA PARTICLEBOARD USING BIO-OIL-BASED PHENOL FORMALDEHYDE (PF) RESIN
}

\author{
NAJA NADIERA OMAR*; ISKANDAR SHAHRIM MUSTAFA*; NURHAYATI ABDULLAH* \\ and ROKIAH HASHIM**
}

\begin{abstract}
Phenol formaldehyde (PF) resin has been extensively used in various branches of industry as adhesive especially in the production of wood-based panels. However, due to the use of expensive and limited petroleum-based phenol in its formulation, there is a strong interest to explore renewable biomass material to partially substitute the phenol. In this work, slow pyrolysis was used to convert oil palm frond into bio-oil. From there, the phenol-rich fraction of the bio-oil was separated and added into the formulation of PF resin to produce an economical and environmental-friendly type of PF resin, known as bio-oil-phenolformaldehyde (BPF) resin. Rhizophora particleboard was then fabricated with the BPF resin as adhesive. The particleboard was found to display excellent mechanical and physical properties with satisfactory formaldehyde emission. A morphological study of the particleboard also supported previous findings. The corresponding atomic number of the particleboard obtained from the morphological study was compared with those of water phantom and a fascinatingly favourable similarity was observed. This finding, hence, proposed a novel higher value-added application of the Rhizophora particleboard which has been largely researched as a potential phantom material in diagnostic radiography.
\end{abstract}

Keywords: oil palm frond, bio-oil, phenol formaldehyde resin, Rhizophora particleboard, phantom.

Date received: 21 July 2016; Sent for revision: 6 August 2016; Received in final form: 18 November 2016; Accepted: 22 November 2016.

\section{INTRODUCTION}

Since 1993, a favourable composition has been found between Rhizophora hardwood and water (Sudin, 1993, Tajuddin et al., 1996; Banjade et al., 2001). When water has been publicly recognised as a phantom material, the favourable composition raised a possibility for Rhizophora hardwood to be used as phantom as well. At first, untreated natural Rhizophora hardwood was employed and it was found that phantom-making from that type

School of Physics, Universiti Sains Malaysia, 11800 Minden, Pulau Pinang, Malaysia.

E-mail: naja.nadiera@gmail.com

** School of Industrial Technology, Universiti Sains Malaysia, 11800 Minden, Pulau Pinang, Malaysia. of hardwood was quite unfavourable since it had poor endurance with time especially after being cut into the desired dimension (Shakhreet et al., 2009). Therefore, the natural Rhizophora hardwood was improvised into a binderless Rhizophora particleboard. As this type of particleboard had no addition of adhesive that would help in binding mechanism, the particleboard was reported to have poor mechanical and physical properties hardly meeting the standard requirement of particleboard to be used in the healthcare industry (Marashdeh et al., 2012).

The use of bio-adhesives such as Arabic gum and Serishoom (traditional animal-based adhesive) were then employed to fabricate the particleboard. Still, the mechanical and physical properties of those two did not provide satisfactory results 
(Abuarra et al., 2014; Tousi et al., 2015). Therefore, the incorporation of widely used synthetic adhesive such as phenol formaldehyde (PF) resin is considered. The selection of this type of resin is mainly due to its ability in providing good moisture resistance, exterior strength and durability as well as excellent temperature stability. However, the main drawback of conventional PF resin is that it can be very expensive due to the phenol price. Hence, the use of more natural and economical product such as bio-oil has been suggested. Bio-oil is a very suitable option because it is rich in phenols which are mainly found within the bio-oil in the form of pyrolytic lignin (Kim et al., 2010).

Several attempts have been made to utilise biooil as phenol substitute in producing the bio-oilphenol-formaldehyde (BPF) resin. These attempts include the incorporation of bio-oil obtained from the fast pyrolysis of pine wood (Sukhbaatar et al., 2009), direct liquefaction of white pine sawdust (Cheng et al., 2011) as well as the fast pyrolysis of white spruce and trembling aspen (Chaouch et al., 2014).

Therefore, instead of using the conventional PF resin that incorporated the addition of petroleumbased phenol, BPF resin that incorporated the addition of natural phenol-rich bio-oil was introduced. This bio-oil was obtained from the slow pyrolysis of oil palm frond, chosen due to its abundant availability across the world. Oil palm frond was usually harvested annually at about $10.9 \mathrm{t} \mathrm{ha}^{-1}$ from more than 13.5 million hectares of oil palm plantation around the world. Since oil palm frond had a very limited utility, an initiative was taken by this work to optimally exploit the enormous amount of oil palm frond (Kelly-Yong et al., 2007). From there, the BPF resin was added during the fabrication of Rhizophora particleboard. The mechanical, physical and morphological properties of the particleboard were also determined.

\section{EXPERIMENTAL}

\section{Materials}

Oil palm frond was harvested in August 2014 in a plantation of Universiti Sains Malaysia (USM), Nibong Tebal, Pulau Pinang, Malaysia $\left(5^{\circ} 08^{\prime} 48.2^{\prime} \mathrm{N}\right.$ $100^{\circ} 29^{\prime} 32.0^{\prime} \mathrm{E}$ ). Oil palm fronds that were left behind from the harvesting process were collected and the leaves attached to them were removed using machete. Immediately after retrieval, the oil palm fronds were dried in a Venticell oven at $105^{\circ} \mathrm{C}$ until their moisture content reduced to less than $10 \mathrm{mf} \mathrm{wt} \%$ to avoid the growth of fungus or microorganism (Abdullah et al., 2014). This moisture content was measured using A\&D MX-
50 moisture analyser and the result was presented in moisture-free weight percentage $(\mathrm{mf} \mathrm{wt} \%)$. Then, a Hitachi band saw machine was used to cross cut the sample to an appropriate length. This was important to ensure that the sample can be milled by a Riken grinder with screen size of $1.5 \mathrm{~mm}$. For that small size of sample, it was hoped that other properties such as particle shape, regularity, surface area and volume ratio which may have an influence on the experimental results will be negligible. The properties of oil palm frond were later determined and presented as in Table 1.

TABLE 1. PROPERTIES OF OIL PALM FROND

\begin{tabular}{lcc}
\hline Properties (wt $\%$ ) & Oil palm frond & Method \\
\hline Structural analysis & & \\
Cellulose & $47.3 \pm 1.1$ & ASTM D1103 \\
Hemicellulose & $27.3 \pm 1.9$ & ASTM D1104 \\
Lignin & $20.1 \pm 2.4$ & ASTM D1106 \\
Extractive & $3.6 \pm 0.1$ & ASTM D1107 \\
Elemental analysis & & \\
C & $42.9 \pm 1.2$ & \\
H & $6.9 \pm 1.4$ & Perkin Elmer \\
N & $0.5 \pm 0.1$ & Series II CHNS/O \\
S & $0.03 \pm 0.02$ & Analyser \\
O & $46.3 \pm 2.4$ & \\
Proximate analysis & & \\
Moisture content & $7.5 \pm 0.3$ & A\&D MX-50 \\
& & moisture analyser \\
Volatile matter & $82.4 \pm 1.4$ & ASTM E872 \\
Ash & $3.4 \pm 0.3$ & ASTM D1102 \\
Fixed carbon & $14.1 \pm 1.6$ & By difference \\
\hline
\end{tabular}

Following that, slow pyrolysis was carried out according to the experimental set-up shown in Figure 1. In a typical run, approximately $200 \mathrm{~g}$ of milled oil palm frond was introduced into a stainless steel pyrolyser and placed inside the reactor. Nitrogen gas was purged into the pyrolyser at $100 \mathrm{ml} \mathrm{min}^{-1}$ to facilitate the removal of pyrolysis vapours into the liquid collection system (Ertaş and Alma, 2010). The reactor was then heated to $375^{\circ} \mathrm{C}$ at a steady rate of $100^{\circ} \mathrm{C} \mathrm{min}{ }^{-1}$. These parameters correspond to the optimised yield of phenols obtained in the biooil (unpublished data). After $1 \mathrm{hr}$ of holding time, the reactor was turned off and allowed to stabilise to room temperature. The bio-oil, as obtained from the condensation of pyrolysis vapours was collected, separated using dichloromethane and analysed as in Table 2 before being used in the synthesis of BPF resin.

\section{Synthesis of BPF Resin}

BPF resin was synthesised according to the previously described method with a slight modification (Chaouch et al., 2014). In brief, 


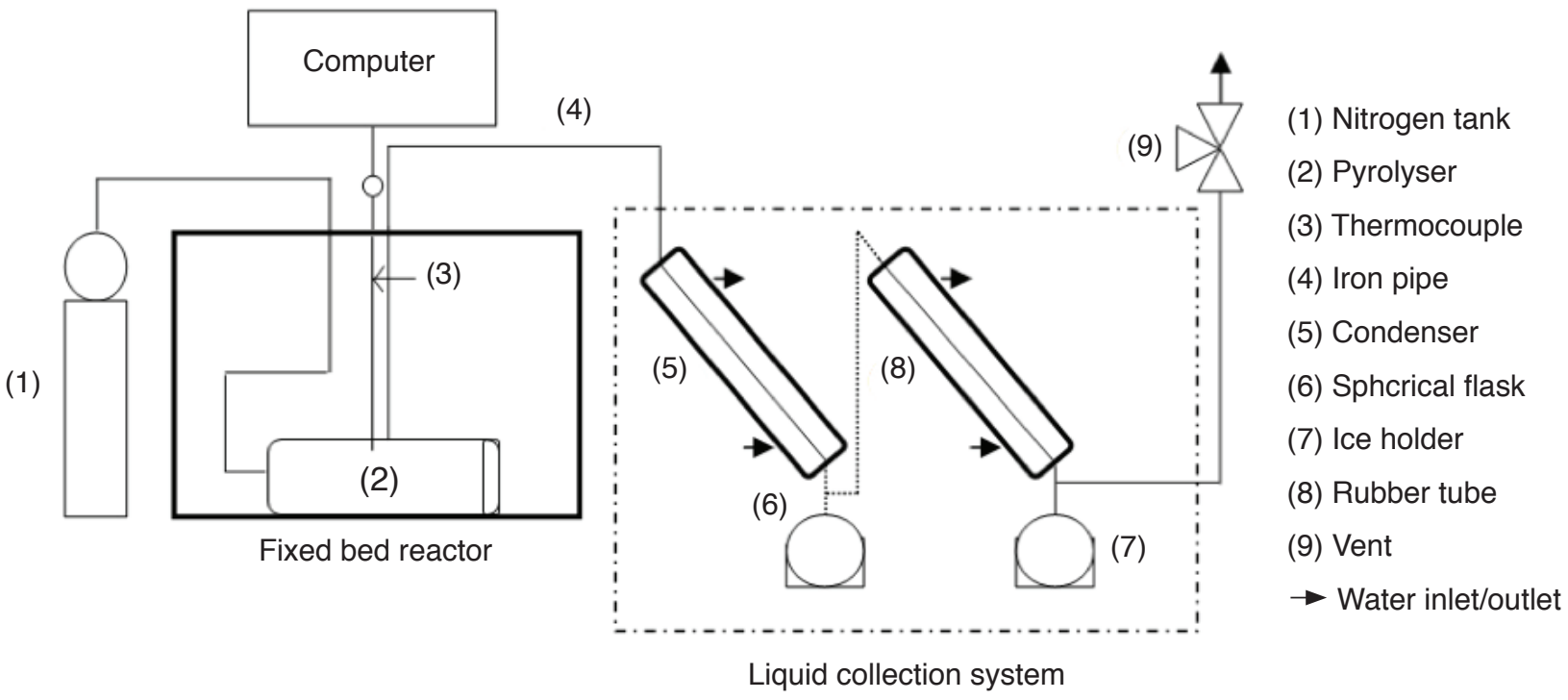

Figure 1. Experimental set-up for slow pyrolysis

liquefied phenol (99\%), bio-oil, anhydrous ethanol $(99 \%)$ and sodium hydroxide $(50 \%)$ were loaded into a resin kettle equipped with a condenser, dropping funnel and thermometer. The mixture was heated to $65^{\circ} \mathrm{C}$ and maintained at that temperature for $30 \mathrm{~min}$ to ensure homogenous alkaline medium

TABLE 2. PROPERTIES OF BIO-OIL

\begin{tabular}{lcc}
\hline Properties (wt \%) & Oil palm frond & Method \\
\hline Element & & \\
C & $66.23 \pm 1.14$ & \\
H & $9.35 \pm 1.16$ & Perkin Elmer \\
N & $0.05 \pm 0.02$ & Series II \\
S & $0.00 \pm 0.00$ & CHNS/O Analyser \\
O & $23.77 \pm 2.30$ & \\
Ash (wt\%) & $0.61 \pm 0.03$ & ASTM D1102 \\
Char (wt\%) & $0.32 \pm 0.13$ & Filtration method \\
pH & $3.01 \pm 0.03$ & Accumet AB15 \\
& & pH meter \\
Total phenols (\%) & 74.39 & \\
Phenol & 40.60 & \\
Phenol, 2-methyl- & 1.69 & Agilent \\
Phenol, 3-methyl- & 2.31 & Technologies \\
Phenol, 2-methoxy- & 8.47 & G890A /5975C \\
4-Mercaptophenol & 1.43 & \\
Phenol, 2,5-dimethyl- & 1.36 & \\
Phenol, 4-ethyl-2-methoxy- & 4.35 & \\
Phenol, 2,6-dimethoxy- & 14.18 & \\
\hline
\end{tabular}

was introduced (Chaouch et al., 2014). After homogenisation has occurred, the temperature was raised to $80^{\circ} \mathrm{C}$ and formaldehyde solution $(37 \%)$ was added step-wise over a period of $10 \mathrm{~min}$. Finally, the reaction mixture was heated to $95^{\circ} \mathrm{C}$ and kept at that temperature for a period of time to allow condensation reaction and polymerisation to occur. After the the required viscosity as seemingly reached the reaction was stopped and allowed to stabilise to room temperature. The BPF resin was then refrigerated in a sealed glass bottle to prolong its pot life by minimising any additional slow polymerisation of phenolic rings (Sukhbaatar et al., 2009). The optimum formulation used to prepare the resin was summarised in Table 3.

For easy reference, abbreviation of $\mathrm{PF}$, $\mathrm{BPF}(\mathrm{OP} 25)$ and $\mathrm{BPF}(\mathrm{OP} 75)$ were used throughout this work denoting conventional PF resin, BPF resin synthesised with $25 \%$ of bio-oil and BPF resin synthesised with $75 \%$ of bio-oil respectively.

The properties of BPF resin were then compared with the properties of conventional PF resin purchased from Asta Chemicals Sdn Bhd. Viscosity measurement was conducted using Visco Basic Plus viscometer with L1 spindle, according to ASTM D1084. The $\mathrm{pH}$ value of the resin was determined using Accumet AB15 pH meter. Meanwhile, the nonvolatile content of the BPF resin was evaluated at 105 ${ }^{\circ} \mathrm{C}$ in reference to ASTM D4426. Free formaldehyde level was measured according to ISO 11402.

TABLE 3. OPTIMUM FORMULATION OF BIO-PHENOL-FORMALDEHYDE (BPF) RESIN

\begin{tabular}{|c|c|c|c|c|c|}
\hline \multirow[t]{2}{*}{ Type of adhesive } & \multirow{2}{*}{$\begin{array}{c}\text { Bio-oil } \\
\text { substituted (\%) }\end{array}$} & \multicolumn{3}{|c|}{ Molar ratio } & \multirow{2}{*}{$\begin{array}{l}\text { Time to reach } \\
200 \mathrm{cP} \text { (hr) }\end{array}$} \\
\hline & & $\mathbf{F} / \mathbf{P}$ & $\mathrm{NaOH} / \mathrm{P}$ & $\mathrm{EtOH} / \mathrm{P}$ & \\
\hline BPF(OP25) & 25 & 1.3 & 0.3 & 0.4 & 5.0 \\
\hline BPF(OP75) & 75 & 1.3 & 0.5 & 0.4 & 3.5 \\
\hline
\end{tabular}


On the other hand, differential scanning calorimetry (DSC) analysis was conducted to evaluate the thermal curing properties of BPF resin using Perkin Elmer DSC Pyris 6. Approximately 10 $\mathrm{mg}$ of resin was sealed in the given DSC aluminium pan, placed onto the sample holder and heated from $30^{\circ} \mathrm{C}$ to $250^{\circ} \mathrm{C}$ at $10^{\circ} \mathrm{C} \mathrm{min}{ }^{-1}$. A flow of nitrogen gas at $20 \mathrm{ml} \mathrm{min}{ }^{-1}$ was maintained over the sample to create a dry and reproducible atmosphere.

\section{Fabrication of Rhizophora Particleboard}

Rhizophora hardwood was also collected in August 2014 from a charcoal factory in Kuala Sepetang, Perak, Malaysia (450'12.1"N $\left.100^{\circ} 38^{\prime} 13.9^{\prime \prime E}\right)$. During the collection, bark of the Rhizophora was removed using bark spud and a total of two bark-free hardwoods were randomly chosen. Immediately after retrieval, the hardwood was dried, cut and milled into less than $200 \mu \mathrm{m}$ using Retsch grinder so that the resulted particleboard had considerable similarity to water phantom (Rabaiee et al., 2015). Then, 10 $\mathrm{wt} \%$ of the BPF resin was mixed with the preweighed Rhizophora particles. The thickness and density of particleboard were fixed at $0.5 \mathrm{~cm}$ and $1 \mathrm{~g} \mathrm{~cm}^{-3}$ respectively, in reference to the required dimension of analysis and density of water.

To compress the mixture, a $23 \times 23 \mathrm{~cm}^{2}$ pressing mould was prepared. This pressing mould was placed on top of a metal plate, covered with aluminum foil to prevent the wood particles from sticking on the metal plate after compression. Then, the mixture was laid evenly within the mould forming a mat. A mould cover was also prepared. The mat was pre-pressed using Bluepoint 001 Heating and Pressing Machine manufactured by Milestone Technology Enterprise at room temperature for 2 to $3 \mathrm{~min}$ before hot-pressed using Fabricate Molding Test Press by GT Instrument Sdn Bhd at $170^{\circ} \mathrm{C}$ for 6 min. After the compression, the particleboard was left to cool down to room temperature before being trimmed and cut for further analysis.
The particleboard was analysed according to JIS A 5908 to determine the mechanical properties such as internal bonding (IB) strength and modulus of rupture (MOR) value as well as the physical properties such as thickness swelling and water absorption. Formaldehyde emission of the particleboard was also measured according to the desiccator method as in JIS A 1460. To analyse the morphological properties of the particleboard, FEI Nova NanoSEM 450 field emission scanning electron microscopy (FE-SEM) was employed at $500 \mathrm{X}$ and 3000X magnification. Following that, the qualitative elemental composition of the particleboard was calculated.

\section{RESULTS AND DISCUSSION}

\section{Properties of Conventional PF and BPF Resins}

The properties of the conventional PF and BPF resins were determined and presented as in Table 4. All BPF resins successfully reached the desired viscosity around $200 \mathrm{cP}$, as in conventional PF resin. The BPF resins also had comparable $\mathrm{pH}$ value to those of conventional PF resin. These two findings were expected since the final viscosity and $\mathrm{pH}$ value of the resins were carefully controlled by varying the condensation time during synthesis procedure and the molar ratio of sodium hydroxide to phenol, respectively.

Furthermore, the non-volatile content of all BPF resins was close and slightly higher than that of conventional PF resin. The high non-volatile content was associated to the small presence of volatile component such as free formaldehyde that was not consumed during synthesis reaction and hence, evaporated during heating period. The amount of free formaldehyde in the resins was indeed small enough to comply with the above deduction.

Free formaldehyde level of BPF resins increased significantly with an increase of substitution level of phenol with bio-oil. This was mostly due to the lower reactivity of bio-oil over phenol or lower

TABLE 4. PROPERTIES OF RESINS

\begin{tabular}{|c|c|c|c|c|c|}
\hline \multirow[t]{2}{*}{ Properties } & \multicolumn{2}{|c|}{ PF (other work) } & \multirow[b]{2}{*}{ PF (this work) } & \multirow[b]{2}{*}{ BPF(OP25) } & \multirow[b]{2}{*}{ BPF(OP75) } \\
\hline & Value & Reference & & & \\
\hline Viscosity $(\mathrm{cP})$ & $250-500200233$ & (Ayrilmis et al., & $209 \pm 3$ & $220 \pm 4$ & $204 \pm 2$ \\
\hline \multirow[t]{3}{*}{$\mathrm{pH}$} & 11.75 & 2008; Zhao et al., & $9.4 \pm 0.0$ & $11.6 \pm 0.0$ & $11.8 \pm 0.1$ \\
\hline & $11.16,10.5$ & 2010; Chaouch et al., & $42 \pm 0$ & $57 \pm 1$ & $43 \pm 0$ \\
\hline & & 2014) & Not detectable & $0.17 \pm 0.05$ & $0.41 \pm 0.04$ \\
\hline Non-volatile content (wt $\%$ ) & $47,64,49$ & Chaouch et al. (2014) & 166 & 154 & 156 \\
\hline Free formaldehyde level (wt $\%$ ) & Not detectable & Zhao et al. (2010) & & & \\
\hline Curing temperature $\left({ }^{\circ} \mathrm{C}\right)$ & 150 & Cheng et al. (2011) & & & \\
\hline
\end{tabular}


number of active sites especially in -otho and -para position to the phenolic hydroxyl group of the biooil which caused poor interaction between phenol and formaldehyde, hence leaving an amount of free formaldehyde at the end of synthesis (Cheng et al., 2011).

Meanwhile, the curing temperature of the resins was represented by the single exothermic peak obtained from DSC result. This curing reaction was important to determine the hot pressing temperature during particleboard fabrication as further condensation and polymerisation would occur, producing a more stable cross-linked resin structure. From the table, it was observed that the curing reaction of BPF resins was obtained at an approximately equivalent temperature. Therefore, with regards to the high value of curing temperature of conventional PF resin, it was right to assume that by $170^{\circ} \mathrm{C}$, all of the resins would have been cured and this temperature would be the most suitable temperature to be used as the pressing temperature of particleboard.

\section{Physical and Mechanical Properties of Rhizophora Particleboard}

Table 5 shows that both the conventional PF and $\mathrm{BPF}$ resins indeed lived up to expectation, as they provided superior IB strength and MOR value when compared to the standard limit of particleboard or when compared to the previous literature; fabrication of Rhizophora particleboard using Arabic gum and Serishoom adhesive (Abuarra et al., 2014; Tousi et al., 2015).

The exceptional strength of the formaldehydebased resins used in this work was mostly due to the interaction of formaldehyde with phenol that created a strong and durable polymer upon condensation and polymerisation. Once cured, this polymer became more stable by the formation of a rigid cross-linked structure, hence further enhancing the mechanical properties of the particleboards.
When different types of resins were employed, no significant change on the IB strength and MOR value was observed, except for a slight increase or decrease according to the viscosity of resins which somewhat affected the mechanical properties (Pizzi and Stephanou, 1994). No significant impact was also seen on the thickness swelling and water absorption, except for a slight variation following the mechanical properties. Mechanical properties of a particleboard affected its physical properties in a way that better bonding contact provided greater resistant to any foreign materials including moisture (Pizzi and Stephanou, 1994).

Furthermore, the significant low value of thickness swelling and water absorption obtained in this work was mostly possible due to the nature of polymer produced from the interaction between formaldehyde and phenol. Apart from providing strong and durable bond, this polymer was known to be less soluble in water. Therefore, the phenolic resin that cured with this type of polymer had a low tendency to interact with water when immersed (Pilato, 2010). Due to that, the thickness swelling and water absorption of the particleboards were lower than those reported in any other work (Abuarra et al., 2014, Tousi et al., 2015).

In addition, all particleboards notably had lower formaldehyde emission than the standard limit with a value ranging from $0.1 \mathrm{mg}$ litre-1 to less than $0.5 \mathrm{mg}$ litre $^{-1}$. The change in formaldehyde emission when different types of resins were used varied according to the free formaldehyde level of resins since the two were inter-connected. Formaldehyde emission of a particleboard was influenced by two different factors. The first factor was the evaporation of unreacted free formaldehyde from the particleboard over time, especially in a high temperature environment. For this reason, any decrease in the free formaldehyde level of the resins caused a reduction in the formaldehyde emission and vice versa. The second factor was hydrolysis reaction that occurred in a high moisture environment. During

TABLE 5. PROPERTIES OF RHIZOPHORA PARTICLEBOARD

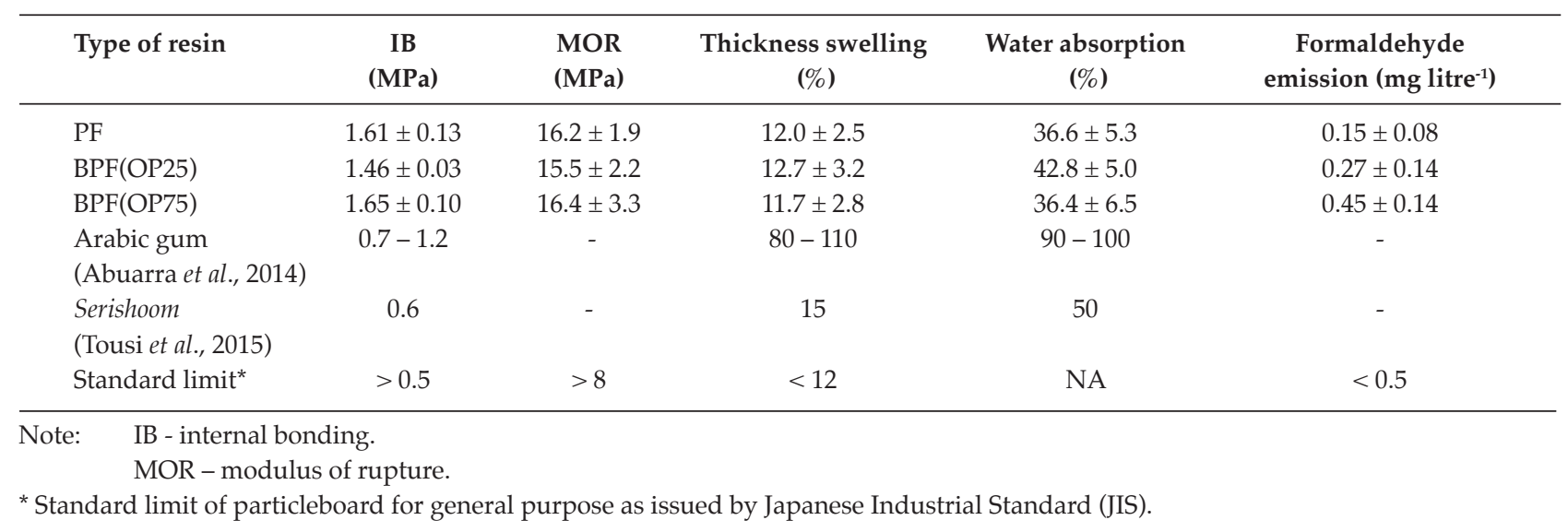


this hydrolysis reaction, chemical bond created from the condensation and polymerisation process was urged to break down. However, since the polymer produced from chemical interaction between phenol and formaldehyde was less soluble in water, the resins provided little susceptibility to hydrolysis reaction. This property made the PF and BPF resins chemically stable and caused lower emission of formaldehyde, than other types of formaldehydebased adhesive, such as urea formaldehyde (UF) resin (Kibert, 2008). A previous work has reported the formaldehyde emission of UF resin by investigating the effect of different compression time of particleboard on the formaldehyde emission. In that work, the particleboard was produced by mixing wood particles with $10 \%$ of UF resin and the resulting formaldehyde emission was shown to decrease from $0.9 \mathrm{mg} \mathrm{litre}^{-1}$ to $0.8 \mathrm{mg} \mathrm{litre}^{-1}$ with an increase of compression time, ranging from $3 \mathrm{~min}$ to $5 \mathrm{~min}$ (Eom et al., 2006). Another work has also been conducted to study the formaldehyde emission of $(40 \times 40 \times 6) \mathrm{cm}^{3}$ plywood bonded with PF resin that had less than $0.1 \mathrm{wt} \%$ of free formaldehyde level. The plywood was prepared using single poplar veneer in the middle and two Eucalyptus veneers on top and bottom of the panel. The veneer was then coated with $0.013 \mathrm{~g} \mathrm{~cm}^{-2} \mathrm{PF}$ resin on each side. The formaldehyde emission of the plywood was analysed using desiccator method and the result was obtained at $0.13 \mathrm{mg}$ litre $^{-1}$ (Zhang et al., 2013).

\section{Morphological Properties of Rhizophora Particleboard}

The micrographs of all particleboards, as obtained from FE-SEM analysis were displayed in Figure 2 until Figure 4. At the magnification of 500X, neither the wood structure of Rhizophora nor the resin network of PF (or BPF) can be identified. Instead, these micrographs showed a rather homogenous blend of network with small amount of void spaces equivalently scattered throughout the surface, hence, indicating a compact distribution within. This compact distribution was produced probably due to the satisfactory mixing procedure as well as efficient compression procedure of the particleboard. Nevertheless, the result was certainly expected since all particleboards produced in this work had a relatively high IB strength and MOR value. The value of the two parameters was greatly influenced by the compactness and homogeneity of the network holding the particleboard together (Abuarra et al., 2014). Furthermore, the presence of adhesive within the particleboards was seen to have a good contact with the wood particles, as observed at 3000X magnification. The balanced interaction between the adhesive and the wood particles consequently enhanced the mechanical properties of the particleboards.
Meanwhile, Table 6 shows the elemental composition of each type of particleboards. Carbon and oxygen were mainly found in the fabricated Rhizophora particleboards, with a trace content of sodium. This finding contradicted with previous work that studied the morphological properties of binderless Rhizophora particleboard which reported that high weight percentage of carbon and oxygen and low weight percentage of nitrogen were found in the particleboard (Marashdeh et al., 2012). This small contradiction was mostly possible due to the addition of the adhesive.

From there, the average atomic number of all particleboards was calculated and compared with those of water (7.42) (Singh and Badiger, 2014). The average atomic number of natural Rhizophora hardwood was previously reported at 7.28 (Marashdeh et al., 2012). In this work, the average atomic number of all particleboards was near to those of water and did not deviate much from the natural Rhizophora hardwood, hence raising its possibility to be used as a phantom material.

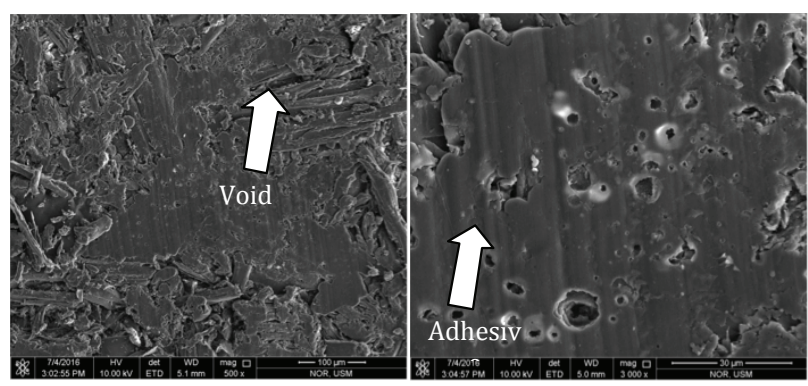

Figure 2. Micrograph of particleboard bonded with 10\% phenol formaldehyde (PF) resin (left: 500X, right: 3000X).

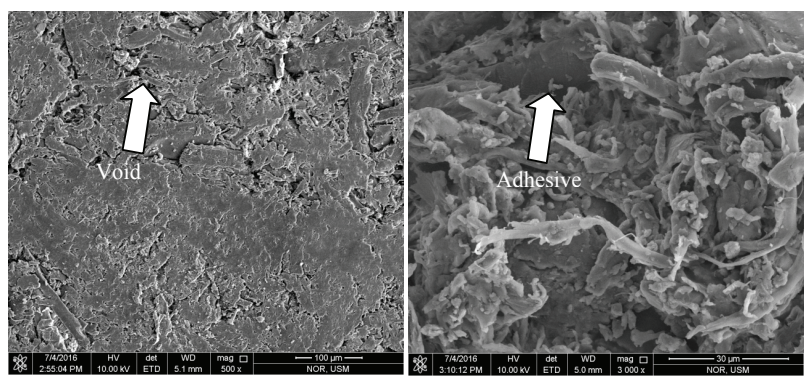

Figure 3. Micrograph of particleboard bonded with $10 \%$ bio-oilphenol-formaldehyde (BPF) (OP25) resin (left: 500X, right: 3000X).

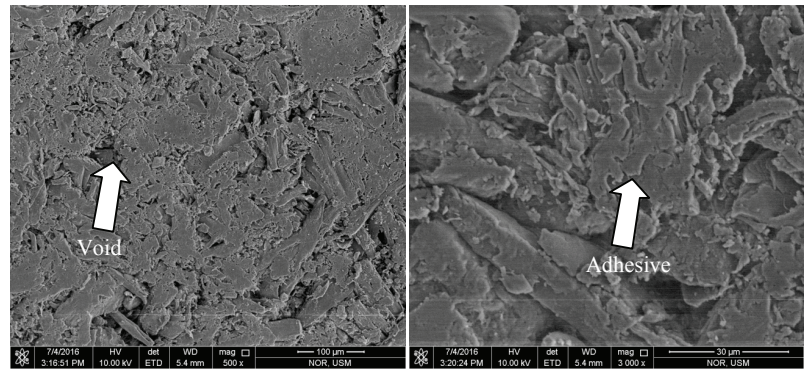

Figure 4. Micrograph of particleboard bonded with 10\% bio-oil-phenolformaldehyde (BPF) (OP75) resin (left: 500X, right 3000X). 
TABLE 6. ELEMENTAL COMPOSITION OF RHIZOPHORA PARTICLEBOARD

\begin{tabular}{lccccc}
\hline Type of adhesive & Carbon & Oxygen & Sodium & Aluminium & Average atomic number \\
\hline PF & 59.60 & 32.41 & 4.16 & 3.83 & 7.53 \\
BPF(OP25) & 51.59 & 40.21 & 8.20 & - & 7.50 \\
BPF(OP75) & 50.21 & 44.95 & 4.84 & - & 7.37 \\
\hline
\end{tabular}

Note: PF - phenol formaldehyde.

BPF - bio-oil-phenol-formaldehyde.

\section{CONCLUSION}

Due to the high similarity and some superiority of the BPF resin, the possibility to fabricate Rhizophora particleboard bonded with this BPF resin was enhanced. The fabrication procedure of this type of particleboard was standardised with those bonded with conventional PF resin to equivalently compare the physical, mechanical and morphological properties. It was found that all the particleboards fabricated in this work showed excellent mechanical and physical properties surpassing the required standard limit issued by the Japanese Industrial Standard (JIS) with satisfactory formaldehyde emission. The morphological properties of the particleboard also supported the previous finding. In addition, it was seen that the average atomic number of the particleboard closely predicted the average atomic number of water. Therefore, further research on the application of the particleboard as a phantom material would be beneficial.

\section{ACKNOWLEDGEMENT}

The authors would like to acknowledge financial supports from Universiti Sains Malaysia under RUI grant (1001/PFIZIK/814250 and 1001/ PFIZIK/811301) as well as Institute Postgraduate Studies (IPS) of Universiti Sains Malaysia under USM Fellowship 1/14.

\section{REFERENCES}

ABDULLAH, N; SULAIMAN, F; MISKAM, M A and TAIB, R M (2014). Characterization of lanana (Musa spp.) pseudo-stem and fruit-bunch-stem as a potential renewable energy resource. International J. Biological, Veterinary, Agricultural and Food Engineering, 8: 712-716.

ABUARRA, A; HASHIM, R; BAUK, S; KANDAIYA, $S$ and TOUSI, E T (2014). Fabrication and characterization of gum Arabic bonded Rhizophora spp. particleboards. Mater Des, 60: 108-115.

AYRILMIS, N; CANDAN, Z and HIZIROGLU, $S$ (2008). Physical and mechanical properties of cardboard panels made from used beverage carton with veneer overlay. Mater Des, 29: 1897-1903.
BANJADE, D; TAJUDDIN, A and SHUKRI, A (2001). A study of Rhizophora spp. wood phantom for dosimetric purposes using high-energy photon and electron beams. Appl Radiat Isot, 55: 297-302.

CHAOUCH, M; DIOUF, P N; LAGHDIR, A and YIN, $S$ (2014). Bio-oil from whole-tree feedstock in resoltype phenolic resins. J Appl Polym Sci, 131: 40014.

CHENG, S; D'CRUZ, I; YUAN, Z; WANG, M; ANDERSON, M; LEITCH, M and XU, C (2011). Use of biocrude derived from woody biomass to substitute phenol at a high-substitution level for the production of biobased phenolic resol resins. J Appl Polym Sci, 121: 2743-2751.

EOM, Y G; KIM, J; KIM, S; KIM, J A and KIM, H (2006). Reduction of formaldehyde emission from particleboards by bio-scavengers. Mokchae Konghak, 34: 29-41.

ERTAS, M and ALMA, M H (2010). Pyrolysis of laurel (Laurus nobilis L.) extraction residues in a fixed-bed reactor: characterization of bio-oil and bio-char. J Anal Appl Pyrolysis, 88: 22-29.

KELLY-YONG, T L; LEE, K T; MOHAMED, A R and BHATIA, $S$ (2007). Potential of hydrogen from oil palm biomass as a source of renewable energy worldwide. Energy Policy, 35: 5692-5701.

KIBERT, C J (2008). Sustainable Construction: Green Building Design and Delivery. John Wiley \& Sons.

KIM, S J; JUNG, S H and KIM, J S (2010). Fast pyrolysis of palm kernel shells: influence of operation parameters on the bio-oil yield and the yield of phenol and phenolic compounds. Bioresour Technol, 101: 9294-9300.

MARASHDEH, M; BAUK, S; TAJUDDIN, A and HASHIM, R (2012). Measurement of mass attenuation coefficients of Rhizophora spp. binderless particleboards in the $16.59-25.26 \mathrm{keV}$ photon energy range and their density profile using X-ray computed tomography. Appl Radiat Isot, 70: 656-662.

PILATO, L (2010). Phenolic Resins: A Century of Progress. Springer. 
PIZZI, A and STEPHANOU, A (1994). Phenolformaldehyde wood adhesives under very alkaline conditions. Part I: Behaviour and proposed mechanism. Holzforschung, 48: 35-40.

RABAIEE, N A; AZIZ, M Z A; HASHIM, R; TAJUDDIN, A A and MALIK, M F I A (2015). Potential of Rhizophora spp. particleboard treated with soy flour as water equivalent material. Jurnal Teknologi, 77: 7-11.

SHAKHREET, B; BAUK, S; TAJUDDIN, A and SHUKRI, A (2009). Mass attenuation coefficients of natural Rhizophora spp. wood for X-rays in the 15.77-25.27 keV range. Radiat Prot Dosim, 135: 47-53.

SINGH, V P and BADIGER, N (2014). Effective atomic numbers of some tissue substitutes by different methods: a comparative study. J Med Phys, 39: 24.

SUDIN, C W (1993). Kayu Tropika Sebagai Bahantara Setaraan Tisu untuk Kajian Dosimetri. M.Sc. thesis, Universiti Sains Malaysia.

SUKHBAATAR, B; STEELE, P H; INGRAM, L I and KIM, M G (2009). Use of lignin separated from bio-oil in oriented strand board binder phenolformaldehyde resins. BioResources, 4: 789-804.

TOUSI, E; HASHIM, R; BAUK, S; SUHAIMI JAAFAR, M; ABUARRA, H; MOHAMMAD, A; MAHMOUD AL-JARRAH, A; ABABNEH, B; TOUSI, A and ALDROOBI, A (2015). Characterization of the Rhizophora particleboard as a tissue-equivalent phantom material bonded with bio-based adhesive. Maderas: Cienc Tecnol, 17: 305-318.

TAJUDDIN, A; SUDIN, C C W and BRADLEY, D (1996). Radiographic and scattering investigation on the suitability of Rhizophora sp. as tissue-equivalent medium for dosimetric study. Radiat Phys Chem, 47: 739-740.

ZHANG, W; MA, Y; WANG, C; LI, S; ZHANG, $\mathrm{M}$ and CHU, F (2013). Preparation and properties of lignin-phenol-formaldehyde resins based on different biorefinery residues of agricultural biomass. Ind Crops Prod, 43: 326-333.

ZHAO, Y; YAN, N and FENG, M (2010). Characterization of phenol-formaldehyde resins derived from liquefied lodgepole pine barks. Int $J$ Adhes Adhes, 30: 689-695. 